error made it 1.213. With my figures and the correct value of the density, the number of molecules in the cell works out at $\mathbf{1} \cdot \mathbf{9 9}$.

Davy Faraday Laboratory,

The Royal Institution,

London, W.1, Mar. 17.

\section{Science and Nature.}

IT is undeniable that the attitude towards Nature which inspired the author of NATURE's motto, is implicitly repudiated by many of its readers. For that spiritual intimacy between Nature and man, which formed the substance of Wordsworth's poetry, is questioned and even rejected by a large body of investigators. To them Nature is the sphere of essentially impersonal energy and law, which are either absolutely indifferent or actively hostile to human ideals. Huxley, for example, regarded the ' cosmic process' as everywhere antithetic to 'social progress,' thus unconsciously destroying the continuity of evolution just where it becomes of supreme value to humanity; and in precisely the same spirit $\mathrm{Mr}$. Bertrand Russell foresees the ultimate extinction, by natural agencies, of everything for which he himself bids us strive.

The validity of such a viewpoint is plainly a matter of the highest scientific importance. For since science is the investigation of Nature, any interpretation of Nature must reflect itself in the interpretation of science itself. Conversely, the implications of science must illuminate the character of Nature; so that quite apart from that fatal breach of evolutionary continuity postulated by Huxley, both the content and the expansion of modern science yield ample material for controverting his conclusion From the strictly psychological viewpoint, all functions of the human mind are fully as natural as those of the brain. It follows, therefore, that reason, logic, and science are just as natural as the cerebral processes which sustain them; and even if any of these are ' emergent,' still this involves no essential loss of continuity. Thus Nature is not only the object of science, but also the sole and primal source of science; and this, still further, not in any merely passive nor indifferent way, but dynamically. For it matters not whether man's intellect is the result of heritable acquired characteristics or of natural selection, since in both respects alike it is the culmination of the age-long interplay of Nature's own agencies. Reason, then, is in no degree foreign to Nature; Nature therefore cannot be foreign, much less hostile, to reason and all that reason involves-to science, art, and morals. Only thus, in fact, can NATURE's motto be accepted in anything beyond a purely metaphorical sense.

Turning next to the specific content of science, it is clear that the logic of science reflects an order of Nature. This remains true even if we regard scientific principles as mere formulæ which enable man to utilise and control Nature ; the sole alternative being the abdication of thought in favour of Bergsonian 'intuition,' which is plainly suicidal so far as science itself is concerned. The truth surely is that science yields an insight, slowly growing in clarity and coherence, into the structure of Nature alike on its physical, vital, and psychical levels. To what degree these are continuous with one another is an important, but here subordinate, problem, since it cannot affect the conclusion that Nature, not partially but throughout its whole extent-from electron to galaxy, from space-time to Shakespeare-is coterminous both with human reason and, so far as man dominates Nature, with human purpose.

It may still be argued that this reciprocity is approaching its final limits, beyond which lies Nature not merely as unknowable, but as inimical. This suggestion, however, definitely contradicts the incessant expansion of modern science. For in all its details alike, scientific progress exemplifies the single fundamental principle that Nature possesses a structure and order so systematic and intricate, so delicate and precise, that all current theories are far too simple to be at all adequate for their understanding and explanation. The solution of every problem without exception reveals fresh problems of ever-increasing difficulty; but in spite of this, increased knowledge shows these to be, in principle, soluble problems. In other words, they are not, essentially, intractable to human reason as such, but only to the limited data with which reason, at any given stage, is condemned to operate; so that as these data slowly multiply, to that degree can more of Nature's riddles be read. Reason thus proves itself to find an ever-widening and favourable habitat within Nature's inmost realm, which thus reveals itself to be no hostile region, but rather thought's highest native sphere.

Nevertheless, the relation between science and Nature must always remain asymptotic ; it can never become exhaustive. But this again is no occasion for pessimism and despair. Rightly understood, on the contrary, it plainly implies that Nature, far from mocking and defying human thought, beckons it ever onward to more intimate contact with herself. For her last secrets will be disclosed only to a reason and a science which transcend our own to the same degree that we transcend Eoanthropus.

\section{J. E. TURner.}

\section{Light and Sight.}

I HAve read Sir John Parsons' article in Nature of Jan. 21 and the letters of Mr. Smith and Sir John (Nature, Feb. 18) with great interest. Perhaps I may be allowed to make a few comments on them. Sir John's supposition was that since the retinal sensation curve reaches its maximum not far from that of the energy curve, and since the two curves are not unlike in shape, there may have been some evolutionary process at work. Mr. Smith's criticism is that only on a wave-length basis would this be the case. If, as is preferable, frequencies be taken, then the shapes of the two curves are quite different.

Now we cannot be sure that Mr. Smith's criticism is justified until we have considered the conditions present in the eye. Until we have done that, have we a pertinent reason for claiming one set of arbitary units (wave-lengths) to be better or worse than another set (frequencies) ?

Now on a wave-length basis, equal wave-length differencies occupy equal areas and all wave-lengths have equal access, since the slit remains fixed in size to give equal wave-length purity. On a frequency basis, on the other hand, equal wave-length differencies do not occupy equal areas, since those of long wave-length are more condensed and those of shorter wave-length more spread out. Neither have all wavelengths equal access, since the slit has to be narrower for short wave-lengths than for long, to give equal frequency purity.

In the eye, on the other hand, owing to the presence of chromatic difference of magnification, shorter wave-lengths are less spread out, and the pupil is slightly wider for short wave-lengths than for long. That is, the conditions present are far removed from the frequency basis and approximate fairly closely to the wave-length one. In view of this, I can see no reason to prefer the frequency basis or to criticise Sir John's suggestion as being impossible. With 